\title{
Haemorrhage in early pregnancy: unusual presentation of placenta increta as complete mole
}

\author{
Priyanka B. Varwatte, Michelle Fonseca*, Deepali Kharat, Jyotsna Dwivedi
}

Department of Obstetrics and Gynecology, LTMMC and GH, Sion, Mumbai, Maharashtra, India

Received: 26 July 2017

Accepted: 22 August 2017

\section{*Correspondence:}

Dr. Michelle Fonseca,

E-mail: priya139.rao@gmail.com

Copyright: (C) the author(s), publisher and licensee Medip Academy. This is an open-access article distributed under the terms of the Creative Commons Attribution Non-Commercial License, which permits unrestricted non-commercial use, distribution, and reproduction in any medium, provided the original work is properly cited.

\begin{abstract}
We report a case of haemorrhage in early pregnancy following suction evacuation for a complete hydatidiform mole which later turned out to be case of placenta increta. Morbidly adherent placenta in early pregnancy a is rare event. There are few reported cases of obstetric hysterectomy in early pregnancy due to undiagnosed morbidly adherent placenta.
\end{abstract}

Keywords: Complete mole, Haemorrhage, Placenta increta

\section{INTRODUCTION}

Placenta increta is a complication of pregnancy that can be life threatening for both mother and fetus. ${ }^{1}$ The abnormally morbid attachment of the placenta might be due to poorly grown decidua in the lower uterine part. ${ }^{2}$

In placenta accreta the chorionic villi grow into the basal decidua within the uterus, whereas these villi in the placenta increta and the placenta percreta go into the musculature and the myometrium of the uterus respectively. ${ }^{3}$

Infiltration in the serosa and even in the neighboring organs such as the urinary bladder and bowel can also occur. Placenta increta is one of the indications of peripartum hysterectomy. It has become common complication due to rising rate of caesarean delivery and repeated curettages. Main risk factor for placenta increta is a previous caesarean delivery. Antenatal diagnosis seems to be key factor in optimizing maternal outcome. Placenta increta is considered as a cause of potentially life threatening intrapartum and postpartum haemorrhage.

\section{CASE REPORT}

A 32 years old G5 P2 A 2 L1 IUFD1, patient had history of previous 1 cesarean section done $11 / 2$ year back for CPD and two spontaneous abortions for which check curettages were done. Patient had complaint of vaginal bleeding following a period of three and half months of amenorrhea. Patient was not sure of her exact LMP. On examination, general condition fair, afebrile, $P R=94 / \mathrm{min}$ $\mathrm{BP}=110 / 70 \mathrm{mmHg}, \mathrm{CVS} / \mathrm{RS}=\mathrm{NAD}$, Pallor ++ . On per abdomen examination soft, no guarding, rigidity and tenderness. On per speculum examination altered bleeding present. On per vagina examination uterus was 12 weeks size, anteverted, cervix high up.

On investigation $\mathrm{HB} \quad 6.4,2$ pint Packed RBCs [transfused, TLC $=11800$ PLT $221000 \mathrm{~T}$ Bilirubin 0.7, AST/ ALT= 19/15 CREAT=0.7 INR=1.0 USG done s/o complete mole, Chest $\mathrm{X}$ RAY done $=$ normal, $\mathrm{ECG}=$ normal, BETA $\mathrm{HCG}=35000 \mathrm{iu} / \mathrm{ml}$. Sr TSH=2.5. After preoperative preanaesthetic evaluation, patient was taken up for emergency suction and evacuation, but during suction evacuation torrential bleeding started, suction evacuation completed and check curettage done 
(perforation was ruled out). iv oxytocin and injection prostodin given but bleeding did not stop therefore procedure abandoned and decision to explore patient taken.

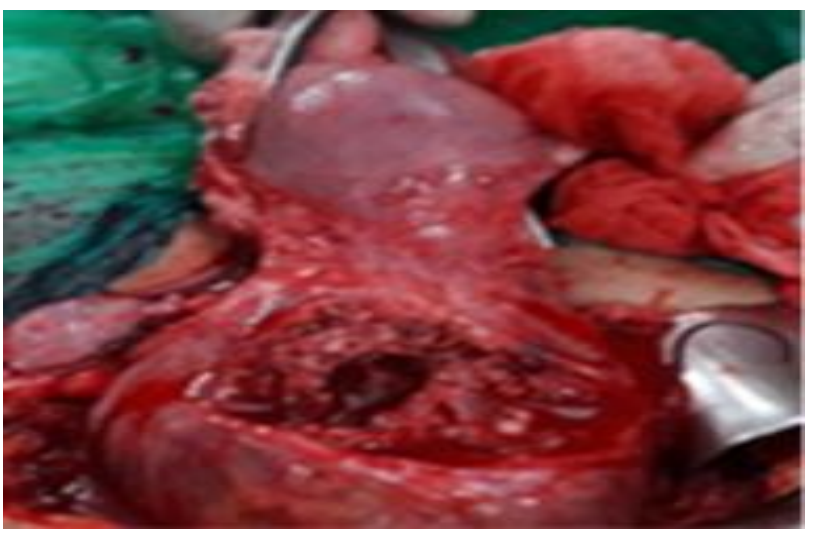

Figure 1: Introp picture of uterus with placenta increta.

Intra op, BP- dropped to 80/60mmhg, P- $130 / \mathrm{min}$. Intraoperatively at the emergency laparotomy, a hemorrhagic mass was seen in the region of the old Cesarean section scars $( \pm 2-3 \mathrm{~cm})$ in the lower segment of the uterus (Figure 1) extending behind the urinary bladder. mass was densely adherent to the uterus and bleeding profusely therefore obstetric hysterectomy was done with clinical suspicion of placental site trophoblastic tumour. Intraoperatively, the total blood loss was estimated at $\sim 1500-2500 \mathrm{ml}$, and 4 units of packed RBCs and 4 units of fresh frozen plasma were transfused. Patients vital signs recovered with inotropic support. Postoperative hemoglobin was $10.1 \mathrm{gm} / \mathrm{dl}$ and the patient did well and was discharged on postoperative day 12 after suture removal. Histopathology of the specimen showed placenta increta with accompanying products of conception (Figure 2).

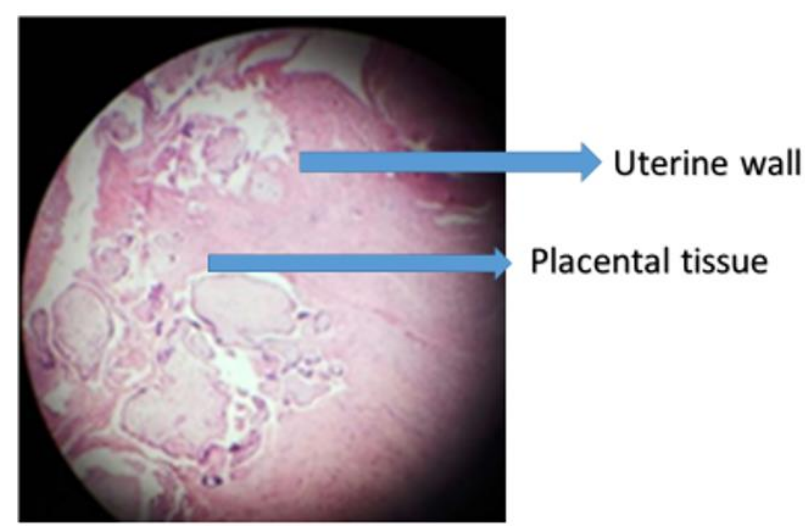

Figure 2: Histopathology report of placenta increta.

There was no evidence of molar changes in the placental villi. Retrospective analysis of the ultrasonographic finding that was interpreted as possible molar changes could have been an evidence of abnormal placental invasion. At such an early stage of pregnancy, a routine ultrasound generally does not include a detailed examination of both localization and implantation of the placenta. Theoretically, it can be assumed that even at this early stage, a detailed ultrasound examination of the uterine wall, in a patient with risk factor for placenta increta, could reveal abnormal placentation. We repeated beta HCG after 1 week which had dropped to $195 \mathrm{IU} / \mathrm{ml}$.

\section{DISCUSSION}

Placenta increta is a major obstetric problem associated with serious surgical co-morbidities; particularly massive hemorrhage $(\geq 3 \mathrm{~L})$. Although the etiology of Placenta increta is unknown, a number of risk factors have been identified on the basis of previous case reports. Of these known risk factors, a history of prior Cesarean section, especially cases with repeated lower segment or classical Cesarean section leaving scar tissue in the anterior uterine wall are most often reported with placenta increta. The diagnosis of Placenta increta is known to be difficult during the first trimester, with a lower accuracy compared with those obtained in the 2nd and 3rd trimesters.

Placenta increta is an intermediate level in the spectrum of abnormal placental villous implantation and accounts for $\sim 20 \%$ of such cases. ${ }^{4}$ The placental villi extend beyond the confines of the endometrium and invades the myometrium. The estimated incidence is increasing (presumably related to increased practice of caesarean sections) and is thought to be around 1:50,000 pregnancies. In placenta increta, chorionic villi invade well into the myometrium but not through the entire wall. Risk factors are similar to other forms of abnormal placental implantation such as previous caesarean section delivery, check curettage etc. Ultrasound as with the less severe placenta accreta, there can be the focal obliteration of the hypoechoic retroplacental zone detected on ultrasound. It was suggested that because of absence or inadequate formation of the decidua, the trophoblast may infiltrate the myometrium. ${ }^{5}$ The abnormally stiff attachment of the placenta might be due to poorly grown decidua in the lower uterine part of the uterus. ${ }^{6}$ Risk factors for an abnormal placentation include prior cervical dilatation and curettage, endometritis, submucous myomas and uterine scars defect after cesarean section. ${ }^{7-9}$ The relationship between abnormal placentation and previous cesarean section was investigated by Clark et al.

\section{CONCLUSION}

With recent advances in ultrasound, attempt should be made to visualize placental attachment at earlier gestation so that emergency situation can be avoided.

Funding: No funding sources

Conflict of interest: None declared

Ethical approval: Not required 


\section{REFERENCES}

1. Gherman RB, McBrayer S, Tichenor J, Wing DA. Placenta increta complicating first-trimester D and C. Obstet Gynecol. 1999 May;93(5 Pt 2):845.

2. Sherer DM, Gorelick C, Zigalo A, Sclafani S, Zinn HL, Abulafia O. Placenta previa percreta managed conservatively with methotrexate and multiple bilateral uterine artery embolizations. Ultrasound Obstet Gynecol. 2007 Aug;30(2):227-8.

3. Kayem G, Davy C, Goffinet F, Thomas C, Clément D, Cabrol D. Conservative versus extirpative management in cases of placenta accreta. Obstet Gynecol. 2004 Sep;104(3):531-6.

4. Grobman WA, Gersnoviez R, Landon MB, Spong CY, Leveno KJ, Rouse DJ, Varner MW, Moawad AH, Caritis SN, Harper M, Wapner RJ. Pregnancy outcomes for women with placenta previa in relation to the number of prior cesarean deliveries. Obstet Gynecol. 2007 Dec 1;110(6):1249-55.

5. Buetow MP. Sonography of placenta percreta during the first trimester. Am J Roentgenol. 2002 Aug;179(2):535-
6. Höpker M, Fleckenstein G, Heyl W, Sattler B, Emons G. Placenta percreta in week 10 of pregnancy with consecutive hysterectomy: case report. Human Reprod. 2002 Mar 1;17(3):817-20.

7. Comstock CH, Lee W, Vettraino IM, Bronsteen RA. The early sonographic appearance of placenta accreta. J Ultrasound Med. 2003 Jan 1;22(1):19-23.

8. Ben Nagi J, Ofili-Yebovi D, Marsh M, Jurkovic D. First- trimester cesarean scar pregnancy evolving into placenta previa/accreta at term. J Ultrasound Med. 2005 Nov 1;24(11):1569-73.

9. Yang JI, Kim HY, Kim HS, Ryu HS. Diagnosis in the first trimester of placenta accreta with previous cesarean section. Ultrasound Obstet Gynecol. 2009 Jul 1;34(1):116-8.

Cite this article as: Varwatte PB, Fonseca M, Kharat D, Dwivedi J. Haemorrhage in early pregnancy: unusual presentation of placenta increta as complete mole. Int J Reprod Contracept Obstet Gynecol 2017;6:4734-6. 